\title{
Através do olho mágico. Reseña del libro En- tre a letra e a tela: literatura, imprensa e cine- ma na América Latina (1896 - 1932), Miriam Gárate.
}

Rio de Janeiro: Papéis Selvagens, 2017.

Hernán J. Morales

Universidad Nacional de Mar del Plata (UNdMP,

Argentina).

«Yo evito el testimonio real, porque me desagradan los confesionarios y esa objetividad eclesiástica del periodismo acusete. Pero tampoco podría negar mi origen y lo evoco en la escritura, travestido, multiplicado en un tornasol engañador. La verdad no me interesa: es paja estancada y filosófica. Como dice Serrat: la verdad no tiene remedio.» (Lemebel, Pedro, Revista Hoy, 1998:58)

«Deve ser coisa importante, pois ouvi a campainha tocar várias vezes, uma a caminho da porta e pelo menos três dentro do sonho. Vou regulando a vista, e começo a achar que conheço aquele rosto de um tempo distante e confuso. Ou senáo cheguei dormindo ao olho mágico, e conheço aquele rosto quando ele ainda pertencia ao sonho. Tem a barba. Pode ser que eu já tenha visto aquele rosto sem barba, mas a barba é táo sólida e rigorosa que parece anterior

ao rosto.» (Buarque, I99i:7) 
Martín Caparrós, periodista y escritor argentino, en una nota publicada bajo el título La crónica, una mirada extrema, ${ }^{\mathrm{I}} \mathrm{y}$ que viene a colación como apertura para este comentario, reflexiona acerca de un género que complejiza no solo la literatura $-y$ por qué no las artes en general- sino también la cultura latinoamericana desde tensiones o desencuentros que pensadores como Julio Ramos (1989) subrayaban en la Modernidad, observando la evolución del pensamiento en estas tierras. América es crónica; es como piensa Caparrós, desde estudios que ligan su mirada sobre tensiones señaladas por Cornejo Polar, Rama, Pizarro, Santiago un espacio de definición que alterna la adaptación entre lo que se conoce y lo no conocido, evidenciando a partir de ello matrices muy conflictivas. Es extrañeza que en un ejercicio recurrente signó el proceso identitario de los habitantes de estas latitudes. Por ello, en esas manifestaciones, las voces «no muestran sino que más bien evocan, reflexionan, construyen, sugieren» para generar un estado de crisis; son textualidades polimorfas que evidencian la ventaja de recrear modos de contar, formas singulares de percibir el entorno, en un ejercicio que pretende despertar al lector, tal como refiere Lemebel en el epígrafe. Son lugares donde la mirada se detiene en un objeto configurado como búsqueda porque la escritura se vuelve práctica extrema, que trasciende el foco periodístico y logra poner en primer plano lo que debería quedar oculto, lo que no se ve a simple vista y necesita ser nombrado. Parece una reinvención del espacio latinoamericano que en narradores contemporáneos (Alma Gillermopietro, Elena Poniatowska, Juan Villoro, Pedro Lemebel, Carlos Monsiváis, entre otros) se torna una obsesión marcada por el ejercicio político que implica el enfrentamiento entre sujeto y su entorno.

Por esa razón, no resulta extraño que Miriam Gárate elija la bisagra de la preposición «entre» para estudiar las relaciones fundantes del cinematógrafo con la literatura y la prensa en América Latina a través de una mirada que se posa sobre las crónicas que circularon en México, Chile, Brasil, Perú, Argentina, entre otros, a fines del siglo XIX y principios del XX. A lo largo de sus 300 páginas, Entre a letra e a tela: literatura, imprensa e cinema na América Latina (I89-1932) ofrece, en una ensayística impecable y sostenida por un gran rigor crítico, un fundamental abordaje de relaciones imbricadas en el discurso de recepción que privilegia el género crónica en el período recortado, y que deja al descubierto el interés por la autora en revisar el impacto del cinematógrafo desde las percepciones 
que los cronistas van manifestando. De modo que desde su originalidad se suturan en el recorrido literatura, prensa y cine en relatos, crónicas, como una forma de recolocarse en el sitio de las miradas escrutadoras de esos cronistas, un reenvío a ese dirigir la mirada que Caparrós destaca como característica fundamental de la crónica a diferencia de la noticia y que la autora recupera de modo atrapante en su prosa.

A través de la «retórica del paseo» (Ramos, 2008), invita al lector a participar de un recorrido que, en la Introducción, se instala como un posicionamiento basado en el estudio minucioso de las circulaciones que los modos de percepción del cinematógrafo fueron adquiriendo en algunos de los periódicos, magazines y revistas de la época en las zonas geoculturales que recorta. Es un modo de análisis - señala la crítica- que toma distancia respecto de una aproximación «literatura/ cine» como enfoque en el problema de la adaptación que privilegia el juego entre «fidelidad e infidelidad». De lo contrario, en el viaje planteado aquí, se aborda un fenómeno periodístico/estético/literario cifrado en un género que continúa a lo largo del proceso de formación cultural de las naciones americanas y que se instituye como uno de los más complejos: la crónica urbana.

En el primer capítulo, «Os escritorescronistas vão ao cinematógrafo», la forma de concepción de los materiales se consolida a través del sustrato: retórica del viaje, por eso la referencia a Ramos, recuperando así voces centrales como las de Manuel González Prada (Perú), José Martí (Cuba), Manuel Gutiérrez Nájera (México), Luis Urbina (México-España), Coelho Neto (Brasil), Olavo Bilac (Brasil), Rubén Darío (Nicaragua), Amado Nervo (México), José Juan Tablada (México-Estados Unidos), Enrique Gómez Carillo (Guatemala-Francia), João do Rio (Brasil), por mencionar solo algunos. En ellos observa Gárate la recreación de una estilística que pone en evidencia el desplazamiento en las crónicas desde lo periodístico hacia lo literario, de ahí el lugar «entre», un hecho que también influye en el nacimiento de un nuevo profesional que se va consolidando en la medida en que esos relatos recrean los impactos del cinematógrafo: el reportero. Aquí destaca el hecho señalado por otros críticos sobre la cuestión de que "a cultura moderna foi "cinematográfica" antes do cinema» y, quizás sea, por esa razón que las miradas de sus cronistas pudieron rápidamente pasar de un instante de asombro a la reflexión crítica.

En esos relatos, y correspondiendo con el primer capítulo, se van configurando las Primeiras viagens; El cinematógrafo de Urbina (I896) y Molestia de época de Olavo Bilac, como relatos que describen la percepción del fenómeno cinematográfico desde construcciones que muestran el proceso de fascinación en referencias 
tales como «máquina milagrosa» y «aparato prodigioso», como así la crónica del mexicano José Juan Tablada México sugestionado: el espectáculo de moda (1906) y En el cine, de Ramón López Velarde. Todo contribuye al despliegue inicial de reflexiones críticas sobre el lenguaje cinematográfico que involucran relaciones con otros géneros, con el teatro y la novela, por ejemplo.

En el segundo capítulo, "Os escritorescríticos se debruçam sobre o cinema» enfatiza el interés de la crítica en torno a la producción del cine, entre el cine narrativo y los modos de leerlos. Sobre todo aquí aparece una cuestión muy estudiada —de ahí la referencia a los teóricos del cine recuperados: Béla Balázs — respecto de cómo se construye y qué características tiene el lenguaje cinematográfico y como dice Gárate, "a linguagem cinematográfica transparente (Xavier, I984) se consolida e disputa com as outras artes a expressão de uma subjetividade inicialmente reservada [imaginariamente reservada] à palabra» (20I7:IO). Las relaciones por ejemplo con otros artes como el teatro y su consecuente comparación con el folletín, Estética del film (I93I) son evidencia de ello. $D a$ "estética da açâo" à estética da subjetivação hay un recorrido que pone de manifiesto las unidades imbricadas en el sistema del lenguaje que se está construyendo y al mismo tiempo su individualización que lo aleja de otras artes: el primer plano, el encuadre y el montaje. Aquí la autora res- cata la visión pesimista de Urbina en esa idea de que «el cine no nutrirá la cultura como el libro» en una contrapunto que pone en primera escena el debate entre espectáculo/cultura y del que refractan tensiones que descubren en este viaje.

En el tercer capítulo, «O retorno do pleito mimético», se debate en torno a las modificaciones en las prácticas culturales manifiestas en la incidencia que tuvo el cine. Rescata en esta sintonía aspectos negativos que los cronistas perciben en relación con una posible influencia entre los crímenes y las películas reproducidas. "O efeito pernicioso do novo espetáculo reside na vivacidade das peripécias que mostram [ensinam] os meios e modos de delinquir» (2017:99). De ahí que exista una prohibición a los jóvenes para que no vean películas que pudieran llevarlos a copiar esos actos en la realidad, así el pleito mimético. Las crónicas, en sus títulos, develan esta arraigada creencia, por ejemplo: «Moralidad, criminología... Lo de siempre. La Razón contra el cinematógrafo", de I919, o frases em los diarios, como "Não acreditamos que a fita torne melhores ou piores os criminosos, mas sim acreditamos que lhes fornece liçóes e os prepara para o delito, dado que a exibição cinematográfica estimula e exalta a imaginação» (La Razón, I919:5). Sin embargo, al mismo tiempo el cine se vuelve un medio para la instrucción o educación a través del cual se brinda una formación moral y escuela del buen gusto, sobre 
todo en crónica de Horacio Quiroga, «El cine en la escuela: sus apologistas» (Caras y Caretas, 1920). Lo que convierte a algunos cines en sitios destinados a instruir señoritas en Perú, un fenómeno que es referido en una crónica que rastrea Ricardo Bedoza. También el espacio para la seducción y las pasiones en Drama y pasión, de Urbina, 1915; Amor, cinema e telefone, de Lima Barreto, 1920, y El cine y la moralidad, de Francisco Zamora, 1919 son muestra de esa pulsión didáctica. Y aún más en la Argentina con El cine $y$ las costumbres, I93I, de Roberto Arlt; y Los problemas con los sexos, en Carlos Nogueira Hope.

En el cuarto capítulo, "Os "latinos" viajam a Hollywood», continuando el recorrido de apertura, la autora trabaja la experiencia del viaje a la gran ciudad cinematográfica como dato significativo que acompaña, entre los años I920y 1930, el gran desarrollo de la cinematografía estadounidense. Elige para enfocar el recorte Una aventura de amor (I9I8) de un cronista con el seudónimo de Boy, Miss Dorothy Phillips, mi esposa (1919) de Horacio Quiroga, Che Ferrati, inventor (1923) de Carlos Nogueira Hope, Hollywood: novela da vida real (1932) de Olympio Guilherme. Dice Gárate:

são narrativas que se estruturam ao redor desse motivo, assim como una série de outros tópicos comuns: o desvendamento das regras que vigoram nos grandes estú- dios bem como de pormenores técnicos e truques de rodagem; o retrato de tipos que se consolidam por esses anos (a flapper, o latino sedutor, o rastaquera); a relaçáo mimética das personagens com modelos propostos pelo cinema (aparência física, atitudes, sentimentos); o enredo amoroso (também ele estreitamente vinculado ao imaginário cinematográfico, o que resulta no entrelaçamento e no revezamento constantes dos registros da «vida» e do "filme»); o vínculo afetivo espectador-estrela; o tema do dublê. (2017:127)

En este escenario se propicia una experiencia que impulsa la «cancelación provisoria de la realidad inmediata», así el viaje se establece no solo como la llegada a la ciudad sino también como la traslación de la vida diurna a la experiencia de fantasía que provoca la oscuridad de la sala sumada a la construcción ficcional del lenguaje cinematográfico, lo que se alegoriza con el par vigilia/sueño que la autora trabaja con el soporte de las teorizaciones de Jean-Louis Baudry (I970) y de Christian Metz (I979). En esta construcción se desarrollan los estereotipos que definen las modulaciones adquiridas por la galería de personajes que pueblan los relatos y que refieren en ese juego de lo ficcional/«lo real» a los latinos que se lanzan a la vida cinematográfica estadounidense: el pobre-diablo, el latino ardoroso encarnados por actores como el argentino Guillermo Grant y el mexicano Federico 
Granados. La autora en este recorrido advierte cómo se configuran en los relatos las operaciones que son parte del lenguaje cinematográfico: el corte/montaje invisible en el recurso gráfico de la línea de puntos en Quiroga y la expresión fade in para intitular las palabras preliminares en la novela de Guilherme como un modo de transferencia entre códigos que se sostiene a lo largo del capítulo a través de un exhaustivo análisis que evidencia al mismo tiempo la maestría con la que Gárate logra suturar los lenguajes.

Finalmente, el libro regresa a las problematizas marcadas inicialmente sobre la base de la hipótesis germinal y que comprueba en una acertada afirmación: durante las últimas décadas del siglo XIX y principios del siglo XX los escritores latinoamericanos realizan una relación estrecha y conflictiva con la prensa modernizada que en la crónica adquiere una de sus manifestaciones más expresivas. Todo esto llega a tal punto que obliga a enfocar realizaciones experimentales vanguardistas que Gárate decide rescatar, quizás, como una cristalización de todas la relaciones señaladas hasta aquí: Pathé-Baby (1926) de Antônio de Alcântara Machado y el film de Alberto Cavalcanti Rien que les heures (1926). Recupera el eje central de su recorrido, la retórica del paseo, porque afirma que la aparición del cine propició la triangulación prensa, crónica y cine generando - tal como asegura - el nacimiento de géneros cinematográficos, tanto desde lo temático como de lo compositivo: las Actualidades, Cine-revista/Cine-jornal o la adopción de títulos como Kinetoscópio, cinematógrafo, vitascópio o cinema da vida. Desde estas líneas y recorridos finales, abreva a que el cine en el siglo XX asume el papel ejercido por la literatura del XIX transformándose en una "máquina de contar historias», como lo hacía el romance folletinesco. En esa sintonía la progresión efectuada por la autora demuestra un interés por desentrañar cómo se funda en los relatos trabajados un viraje producto de ese desplazamiento que va del periodismo a la crónica, pasando por la novela y, finalmente, al cine en siglo pasado, lo que señala una ruptura de categorías genéricas que resalta tensiones. Por eso no resulta extremo que, tal como alude la imagen "A vendedora de jornais», que ilustra la tapa de su libro en un homenaje a Alberto Cavalcanti, se pregunte hacia el final del volumen y como modo de continuar su pensamiento, de descubrir lo que está más allá del olho mágico de la lente: ¿Rien que les heures: uma crônica de celuloide? 
Referencias bibliográficas

- CAPARRÓS, M. (2007). La crónica: una mirada extrema.

Diario La Nación. Recuperado de: http://www.lanacion.com.

ar/943086-la-cronica-una-mirada-extrema

- RAMOS, J. (1989). Desencuentros de la modernidad en América

Latina. México: Fondo de Cultura Económica.

- BUARQUE, C. (1991). Estorvo. Rio de Janeiro: Companhia das letras.

- SCHAFFER, M. (febrero de 1998). Pedro Lemebel. La yegua silenciada. Hoy, (1072). Recuperado de: http://www.memoriachilena.cl/archivos2/pdfs/MC0044778.pdf 